G enau einen Tag nachdem Manfred Fabricius diese Übersetzung eingereicht hatte, wurde mir José F. A. Oliver anlässlich einer Dichterlesung im Goethe Institut Madrid vorgestellt. Der erlebten, da er seine Gedichte wirklich inszenierte. Die Bewegungen seiner Hände und die Mimik seines Gesichts interpretierten visuell seine Verse und gaben ihnen eine neue Ausdruckskraft, die ich beim

\title{
JOSÉ F.A. OLIVER IN SEVILLA
}

\section{Hiltrud Hengst. I.E.S. San Isidoro. Sevilla}

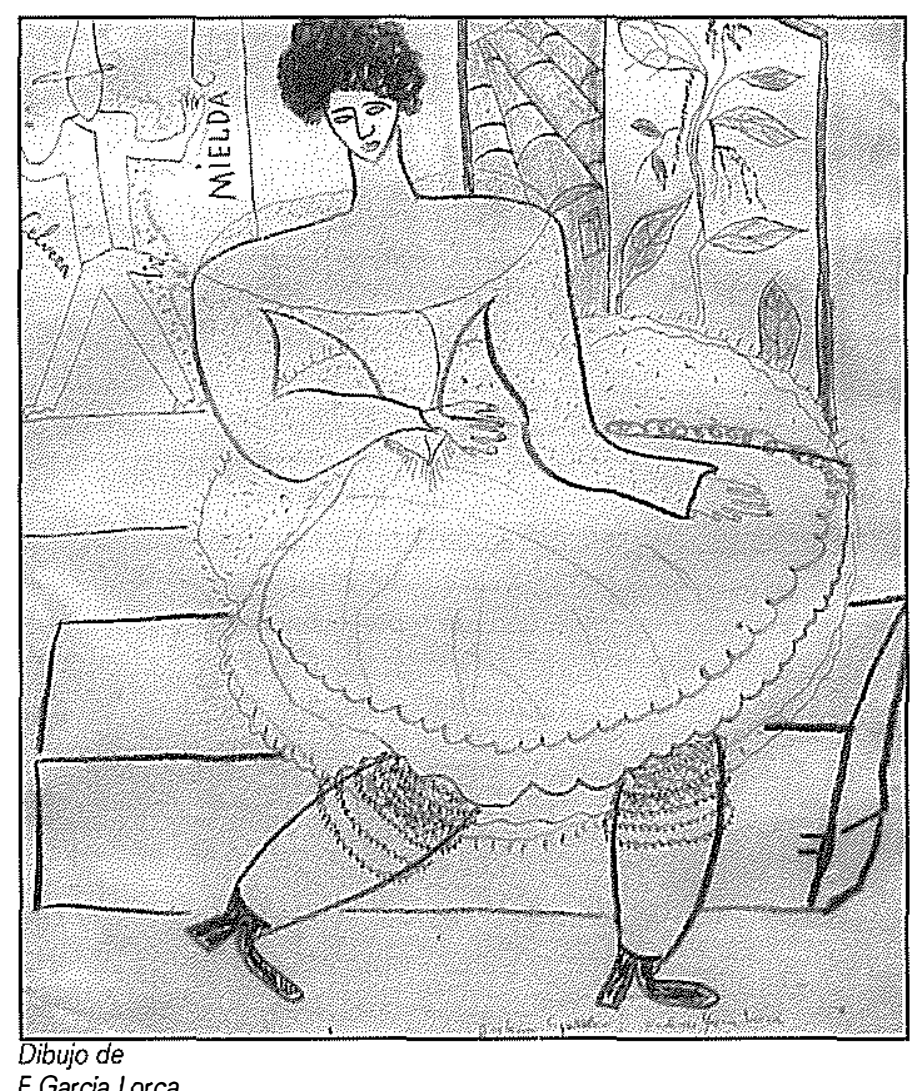

Zufall wollte, dass er einige Wochen später in Huelva zum Iberoamerikanischen Filmfestival eingeladen war und in Verbindung damit bereit war, für die andalusischen Deutschlehrer und Studenten einen Tag nach Sevilla zu kommen.

Am 27. November trat er dann vor einem vornehmlich studentischen Publikum in der Universität Sevilla auf. Ich nenne es bewusst einen "Auftritt" und nicht Lesung oder Vortrag, was wir an diesem Abend dort vorherigen Lesen nicht erwartet hatte. Ausserdem eröffnet er dem Zuschauer ihre musikalische Dimension, indem er sie beeindruckend "aflamencado" sang, mit der Gitarre begleitete oder sprechend rhythmisierte. Diese dramatisch orchestrierte Interpretation machte mir seine Gedichte auch semantisch viel einsichtiger. Ich verstand auf einmal mehr als nur den Text, denn nun komplementierten sich mehrere Sinne, und in mir wurde die Erinnerung an das Gedicht "Corresponce" von Baudelaire hervorgerufen, wo diese unerwartete Symbiose beschrieben wird.

Ebenso spürte ich ständig in seinen ausdrucksstarken Metaphern und die Phantasie anregenden Wortschöpfungen sowie in seinen schnellen, kurzen oder dramatisch anschwellenden Rhythmen die Spuren der andalusischen Dichtergeneration von 1927. Es gelingt ihm, diese andalusische Welt auf eine ganz eigentümliche und einzigartige Weise in die deutsche Sprache zu verpflanzen. Indem die einfache Leichtigkeit der "Nanas", die bedrohlich sich in den Tod steigernden Rhythmen der Romanzen oder spanisch angehauchte Wortschöpfungen wie "die Mondin", (Lorcas "luna"), "die Meerin", (Albertis "mar") oder eine so andalusische Evokation wie "zitronenfalterfügelleicht" in seine Poesie aufnimmt, bereichert er die deutsche Dichtersprache. Bei seinen freien Erfindungen nutzt er gleichzeitig die Möglichkeiten beider Sprachen: die Freiheit der Wortzusammensetzungen des Deutschen und die von der südlichen Natur geprägten Bilderwelt des Spanischen. Metamorphosierend steigert er sie ins Extreme, so dass sie kaleidoskopisch Bilder evozieren, die trotz ihrer Konkretheit im Detail über die Grenzen der menschlichen Vorstellungskraft hinausgehen. 
Aber nicht nur in diesen poetischen Aspekten, sondern auch in seinem Selbstverständnis als Dichter, der etwas bewegen will, kommt er seiner Vorläufergeneration nahe. In seinen Versen verflechten sich persönliche Erfahrung und Selbstreflektion über "die unsichere Fremde" immer wieder mit sozialpolitischen Ereignissen, die uns wachrufen, damit wir Mölln, Auschwitz, Jerusalem oder die Mauer nie vergessen.

Beeindruckend war für mich, wie er schilderte, dass seine Mutter in den "heissen" Monaten des Fremdenhasses nach Mölln in seinem Heimatdorf auf der Strasse angegriffen und verwundet worden war und blutend ins Zimmer kam, wo sein unter Multiple Sklerose leidender Vater hilflos im Rollstuhl sass. Unfähig seine Frau zu verteidigen, schien er den Entschluss zu fassen, den Kampf ums Leben aufzugeben. Ich fühlte eine wahnsinnige Wut und trauernde Ohnmacht, schämte mich, eine Deutsche zu sein und in mir stieg ein Ekel auf gegen alle Deutschen, die solche Geschehen verharmlosen.
Auch für José F.A. Oiver war dieser Aufenthalt in Andalusien ein besonderes Erlebnis, obwohl er, wie er richtig bemerkte, eigentlich nicht "zurückkommt", da er hier nie gelebt hat. Aber er möchte die neu geknüpften Beziehungen zu Andalusien weiterauszubauen und mit Institutionen wie der Stiftung von Juan Ramón Jiménez in Moguer intensiv zusammenzuarbeiten. Zu seinen nächsten Projekten zählen u.a. die Übersetzung seiner Gedichte ins Spanische und der Gedichte León Felipes oder später vielleicht auch Lorcas ins Deutsche.

Er fühlt sich besonders Juan Ramón Jiménez verbunden, weil er ein internationaler, allem gegenüber offener Dichter ist. José Oliver lebte auch zwölf Jahre in Peru, wo er für "los niños de la calle" arbeitete. Nach seinen vielen geplanten Lesungsreisen besonders in Südamerika, hoffen wir, dass es ihn wieder bald nach Andalusien "zurück"bringt.

H.H.
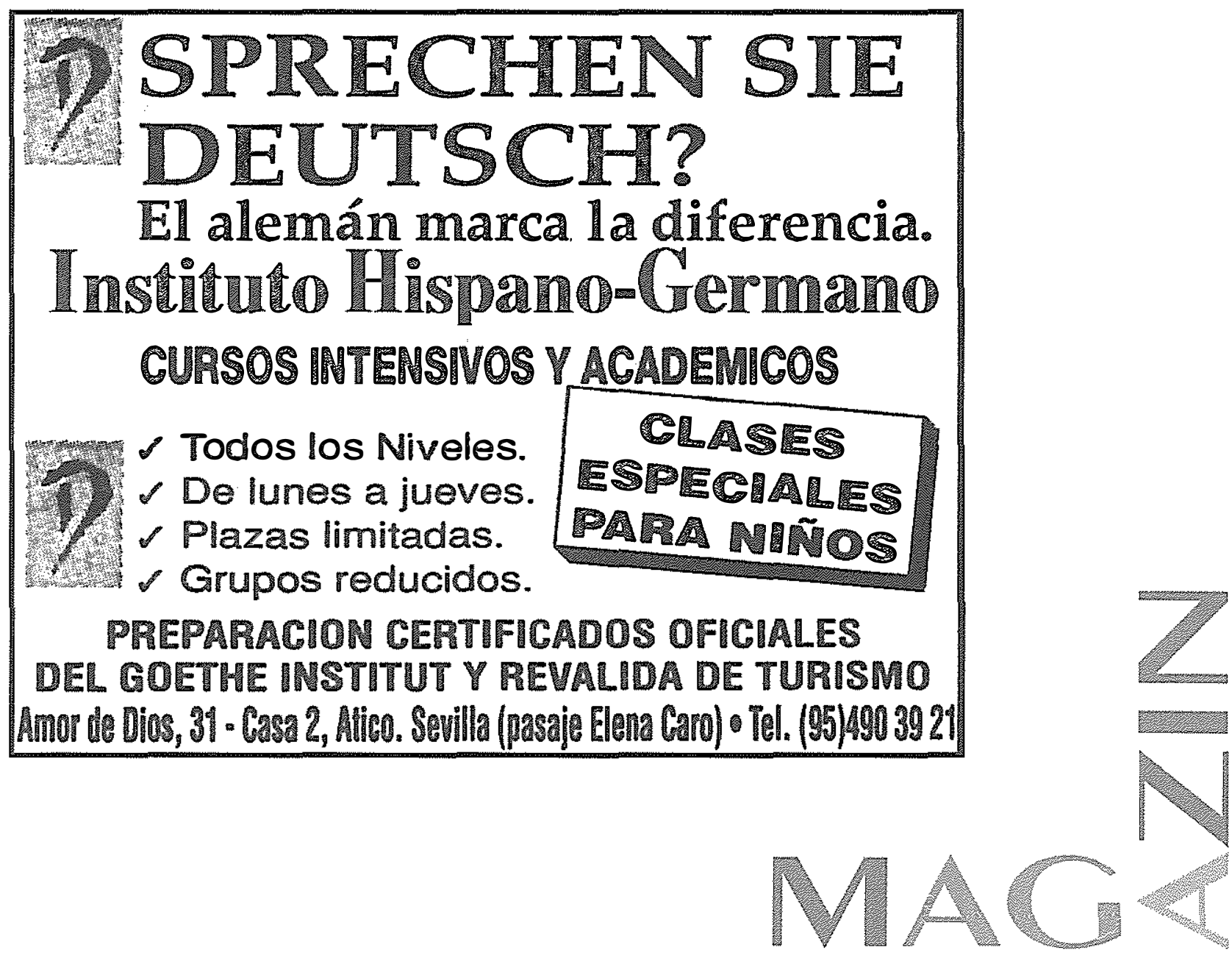